\title{
IoT blood pressure monitoring system
}

\author{
Norlezah Hashim ${ }^{1}$, Nurbahirah Norddin ${ }^{2}$, Fakrulradzi Idris ${ }^{3}$, Siti Nur Ilmani Mohd Yusoff ${ }^{4}$, \\ Madiha Zahari ${ }^{5}$ \\ ${ }^{1,4}$ Centre for Telecommunication Research \& Innovation (CeTRI), Fakulti Teknologi Kejuruteraan Elektrik dan \\ Elektronik (FTKEE), Universiti Teknikal Malaysia Melaka (UTeM), Malaysia \\ ${ }^{2,5}$ Centre for Robotics and Industrial Automation (CeRIA), Fakulti Teknologi Kejuruteraan Elektrik dan Elektronik \\ (FTKEE), Universiti Teknikal Malaysia Melaka (UTeM), Malaysia \\ ${ }^{3}$ Centre for Telecommunication Research \& Innovation (CeTRI), Fakulti Kejuruteraan Elektronik dan Kejuruteraan \\ Komputer (FKEKK), Universiti Teknikal Malaysia Melaka (UTeM), Malaysia
}

\begin{tabular}{|c|c|}
\hline Article Info & ABSTRACT \\
\hline Article history: & $\begin{array}{l}\text { The number of patients in hospital keep increasing every year and, some } \\
\text { patients's blood pressure must be measured by medical staff regularly. }\end{array}$ \\
\hline Received Feb 5, 2020 & This means that the medical staff need to attend to the patient routinely and \\
\hline Revised Mar 21, 2020 & several readings are required in each session to make sure the results are \\
\hline Accepted Apr 3, 2020 & $\begin{array}{l}\text { accurate. Therefore, there is a need to simplify the monitoring process inside } \\
\text { hospital in Malaysia. In this work, IoT Blood Pressure Monitoring System }\end{array}$ \\
\hline Keywords: & $\begin{array}{l}\text { (IBPMS) is designed to monitor patient's blood pressure remotely. } \\
\text { This project use Raspberry } \mathrm{Pi} \text { as a gateway to view the value of blood }\end{array}$ \\
\hline Blo & pressure online. Result showed that the design is capable to transfer data \\
\hline Gmail & from blood pressure detector through the network using USB TTL serial \\
\hline IoT & $\begin{array}{l}\text { which is directly attached to the Raspberry Pi. User can also view } \\
\text { blood pressure reading continuously from Telegram application and }\end{array}$ \\
\hline Raspberry Pi & $\begin{array}{l}\text { the blood pressure reading contınuously from lelegram application and } \\
\text { email service. Furthermore, the system can measure the value of blood }\end{array}$ \\
\hline Telegram & essure accurately when user is in sitting position. \\
\hline
\end{tabular}

Copyright (0) 2020 Institute of Advanced Engineering and Science. All rights reserved.

\section{Corresponding Author:}

Norlezah Hashim,

Centre for Telecommunication Research \& Innovation (CeTRI),

Fakulti Teknologi Kejuruteraan Elektrik dan Elektronik (FTKEE),

Universiti Teknikal Malaysia Melaka (UTeM),

Hang Tuah Jaya, 76100 Durian Tunggal, Melaka, Malaysia.

Email: norlezah@utem.edu.my

\section{INTRODUCTION}

The National Audit Department mentioned in its most recent report that emergency and trauma departments (ETD) at certain Malaysian hospitals were overcrowded, understaffed, underfunded and under equipped. The number of patients keep increasing and the Ministry of Health (MOH) must shoulder the heavy liability of providing health to the best of its capacity to all Malaysians. Thus, there is a need to simplify the monitoring process inside the hospital in Malaysia. It is easier to have online monitoring system to show every condition in engineering [1]. One method is to use Internet of Things (IoT) to monitor the patient's health. Nowadays there are a lot of applications being designed and implemented to increase the efficiency of hospital's management [2]. IoT blood pressure monitor is designed and developed to help the hospital's staffs monitoring the blood pressure reading of a patient remotely. This will reduce the dependability of the patients towards the hospital's staffs as well as enhancing how doctors make their decision based on patient condition at real time. IoT blood pressure monitor is also valuable for elderly or disability patients who might have difficulty to go to the hospital to check on their condition. The system is able to expand the medical services setting from patient's home to the doctor's facility. 
Recently numerous researches had evolved the blood pressure monitoring system from many sorts including electronic sphygmomanometer, conventional sphygmomanometer and aneroid sphygmomanometer. Baharuddin in [3] mentioned two methods that can be used to measure the blood pressure, first method is using stethoscope and the second method is the automated type which is by the usage of high technology. Monitoring system based on IoT was discussed in [4, 5] using ZigBee technology. Ling in [6] proposed a blood pressure monitoring device which can connect to a computer and record the information but no IoT was implemented so far on the system. The research project proposed by Chao Li in [7] aims only at heart disease issues and not blood pressure. Numerous medical devices sensors were combined to analyse the rate of the heart disease patient. Dimitrios and Jonathan [8] suggested the design of IoT technologies have to enact universal design in order to better include elderly in managing their health and improving quality of life. Jahan in [9] used NRF module and LM358 sensor to measure systolic blood pressure and the results were compared with sphygmomanometer readings. An application system introduced by Salah in [10] measures the pulse rate and blood pressure of the swimmer and transmits the values to the rescuer mobile application. Smart healthcare monitoring system proposed by [11] used Node MCU connected to WiFi for sending patients health information and provides an alert by sending an email. $\mathrm{Li}$ in [12] developed a wireless blood pressure monitoring system using Zigbee and the system is observed using personal computer. Priyanka in [13] has developed health monitoring system using Arduino and Blynk Application. In this paper, ESP32 development board was used to enable the IoT function using WiFi. The proposed work in [14] developed a health monitoring system using GSM and raspberry pi module where the system able to send messages to the doctor in order to be subsequently analyzed for medical opinion. In [15], an IoT system is proposed and developed with the help of oxygen saturation ( $\mathrm{SpO} 2)$ measurement sensor, blood pressure sensor, temperature sensor, Bluetooth, Arduino. Bolivar in [16] presented the development of a wireless communication prototype, based on a physical arterial blood pressure monitor which will be able to send data to a web server due to ESP8266 Wifi interconnection module. An Arduino based health monitoring system was suggested by [17] where the data will be sent to computer for monitoring using LabView software. In [18], the Raspberry pi module was used as the microcontroller to send the health monitoring status of a patients to the server. Healthcare monitoring system was suggested by [19] where the data was sent to a webpage, which updates every two minutes.

A lot of previous works used database to monitor the developed system, where in this work the output is sent to mobile application and Gmail rather than personal computer. The suggested system in this paper has advantage in term of mobility, where the doctor or the hospital staff able to monitor the patient whenever possible. The rest of the paper is organized as follows. Part 2 explains the overview of the research method used in this paper. Results and analysis are elaborated in Part 3 and finally, the author concludes the findings of the paper in Part 4.

\section{RESEARCH METHOD}

This project consists of software and hardware implementation. The block diagram of the system designed is explained in Figure 1. The overall system is controlled by Raspberry Pi that able to detect data from the blood pressure device and send them over the internet for user to view it from Telegram and mail application. This application can be observed by anyone who has the authorities to access the data and information inside the server.

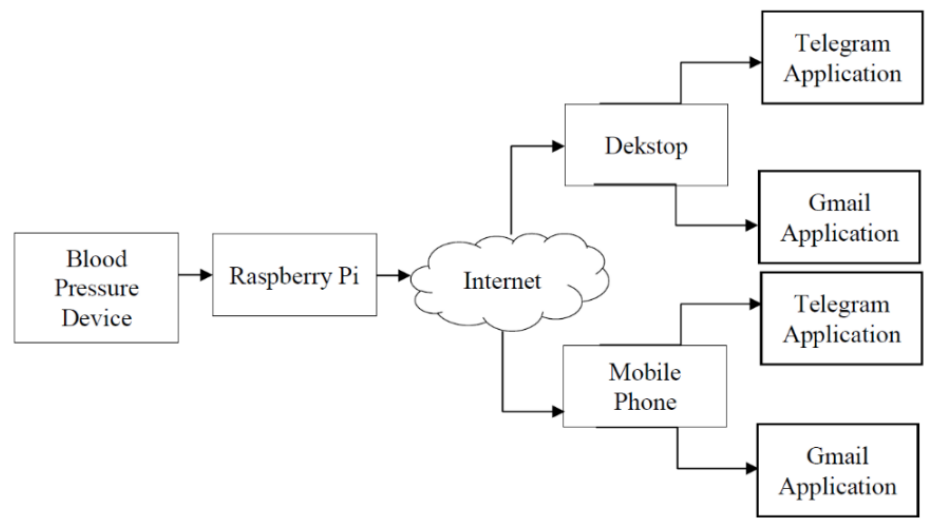

Figure 1. System block diagram 


\subsection{Software configuration}

In order to complete the project, few softwares have been used to make sure the implementation can be done successfully. H-term is a monitoring tool used to read and view the serial data transferred from blood pressure detector to Personal Computer (PC). Figure 2 shows the display in H-term software where it able to display three types of data appears on the blood pressure detector continuously. Putty is another software tool used in this project where it was being used for network file transfer application. PuTTy is the medium software to run the program to execute on Raspberry Pi. To use PuTTy, one must make sure the IP address from Raspberry Pi has been checked and insert correctly. This is done to make sure the PuTTy can communicate with the Raspberry Pi device. Figure 3 shows that the PuTTy Software is used as a medium to run Python Programming language.

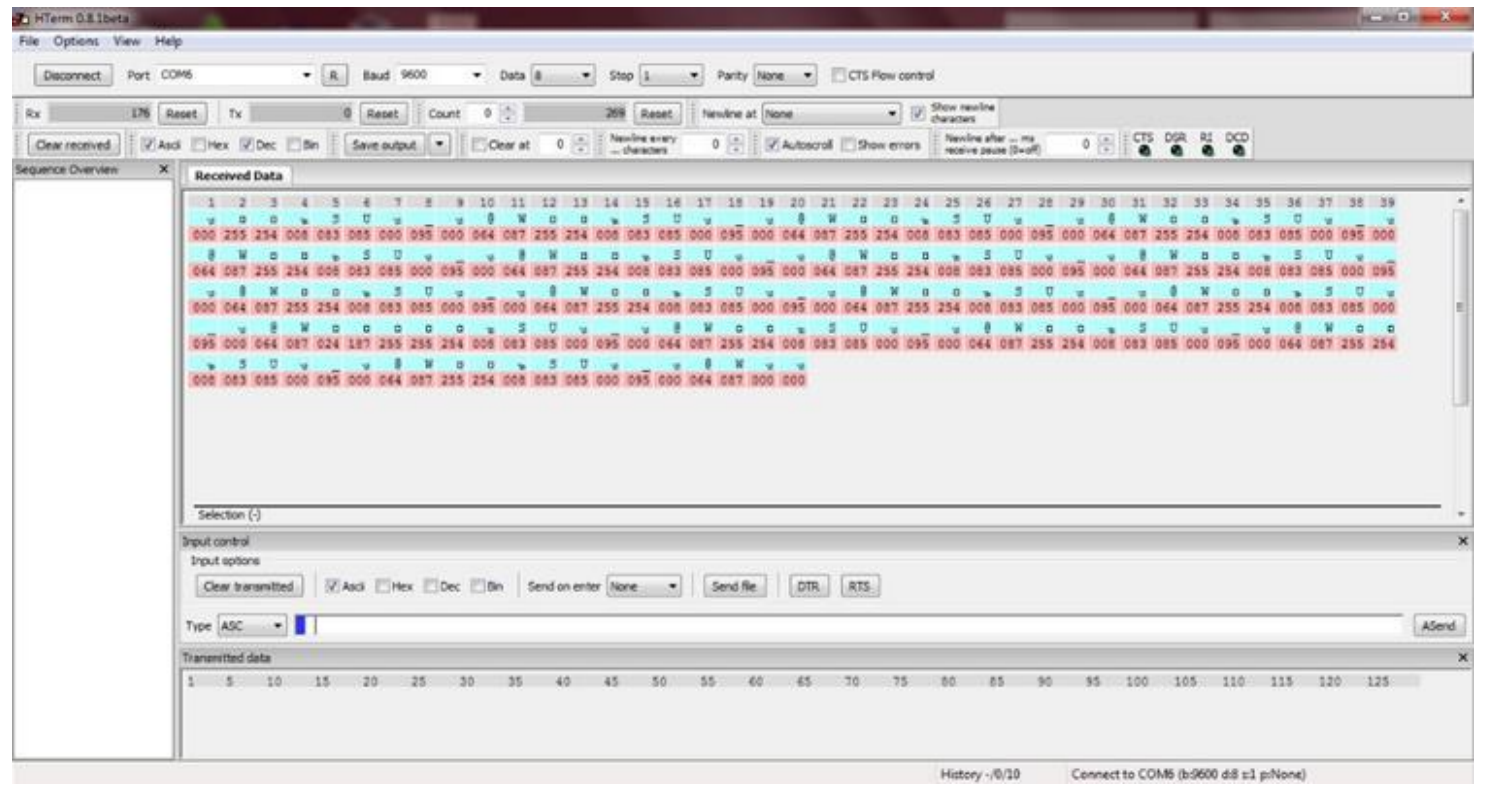

Figure 2. H-term software

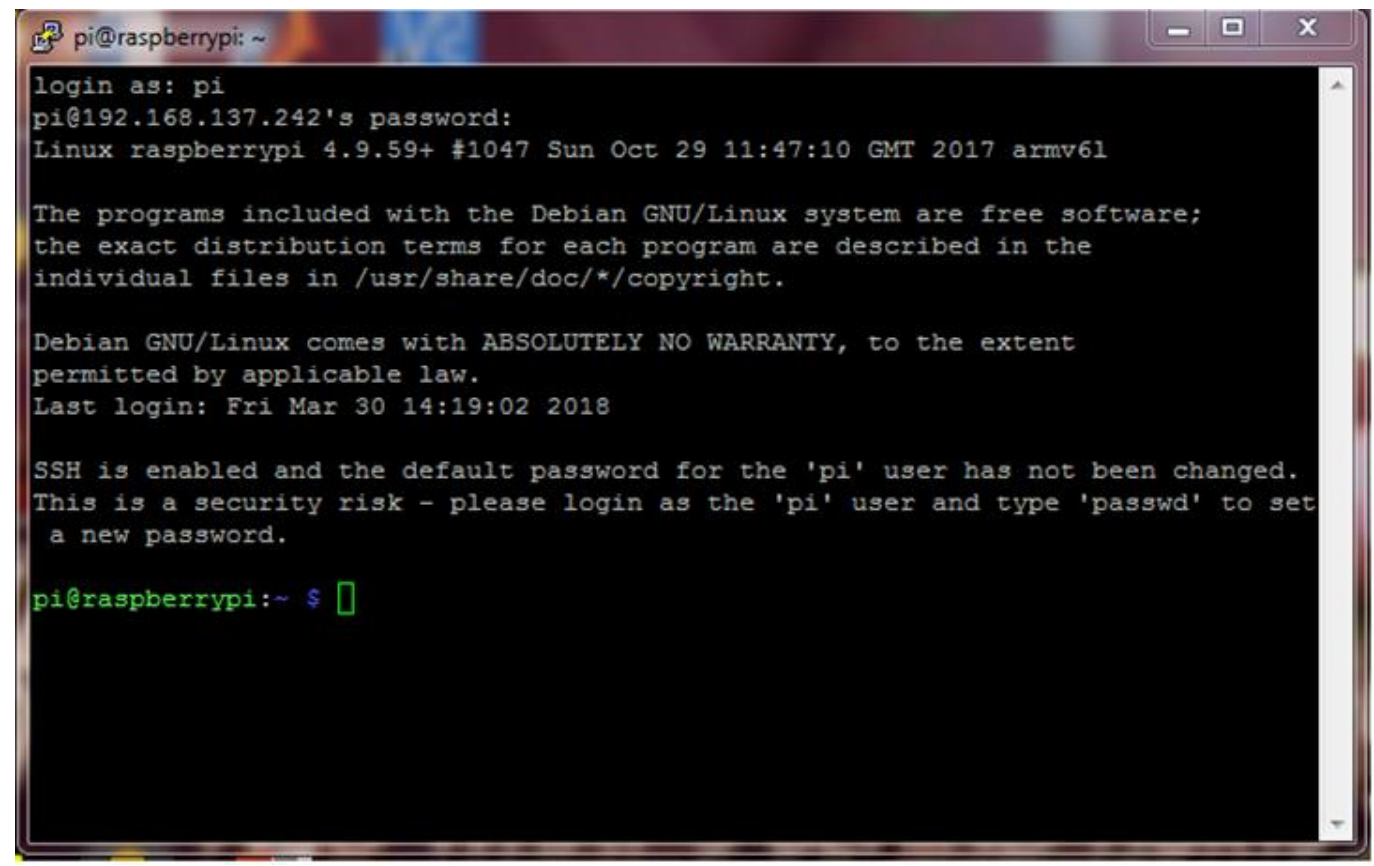

Figure 3. Putty software 
The system flowchart is shown in Figure 4. The system starts when a user switch on the blood pressure device. The user then has to wait for the device to obtain the blood pressure measurement. The output will be displayed at Juice SSH Application before being transferred to email and Telegram application. JuiceSSH is a useful Android application that able to manage Linux servers easily.

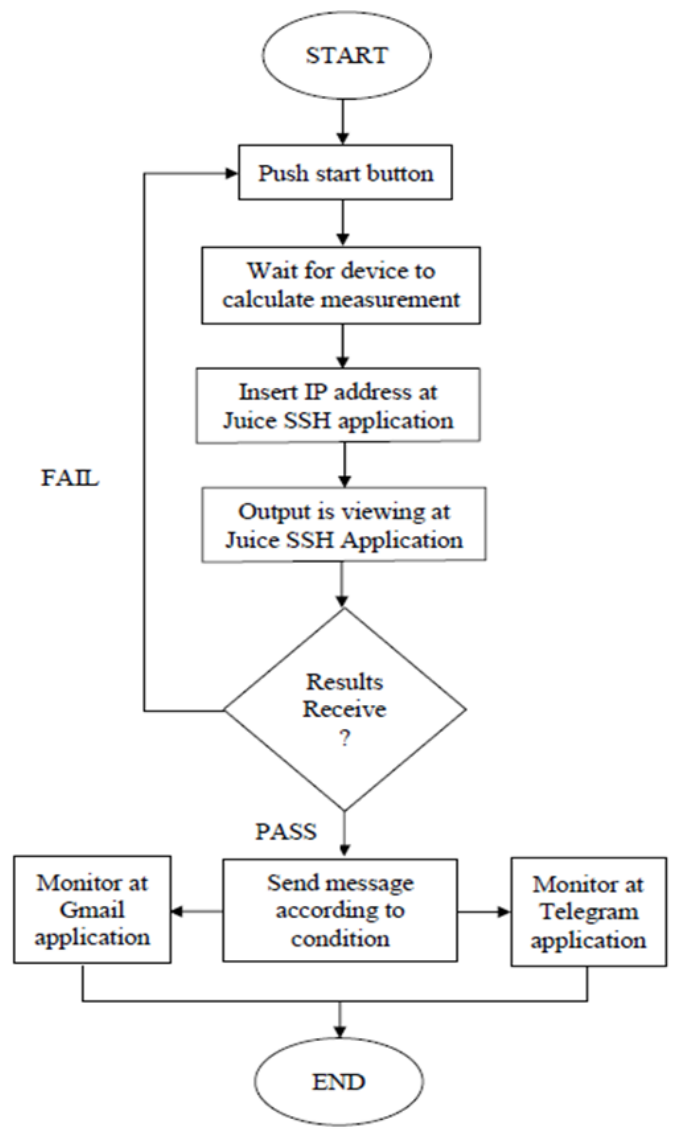

Figure 4. System flowchart

\subsection{Hardware Configuration}

Universal Serial Cable (USB) to TTL Serial cable is used to transfer the data obtained from the blood pressure detector to a personal computer (PC). There are two methods of internet connectivity in this project, by using Ethernet cable and wireless adapter. Raspberry Pi model B+ V1.2 is used in this project where it has 40 General-Purpose Input/Output (GPIO) pin. Raspberry Pi required 5 volts to power on the device and it can be done by connecting the USB cable to the PC. The blood pressure device used in project is a wrist type that has the model number CK101. The blood pressure data from Electrically Erasable Programmable ReadOnly Memory (EEPROM) will be transferred to PC by using USB to Universal Asynchronous ReceiverTransmitter (UART) cable. Figure 5 shows the blood pressure device used in this project.

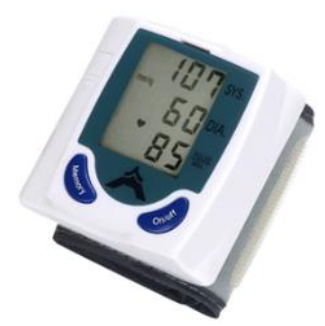

Figure 5. Blood pressure device model 


\section{RESULTS AND ANALYSIS}

Figure 6 shows the completed designed prototype. The blood pressure detector which is a wrist type is connected to Raspberry Pi using a USB cable. Raspberry Pi is then connected to WiFi dongle for internet connection. A wireless connection is needed in order to transfer the data over the internet.

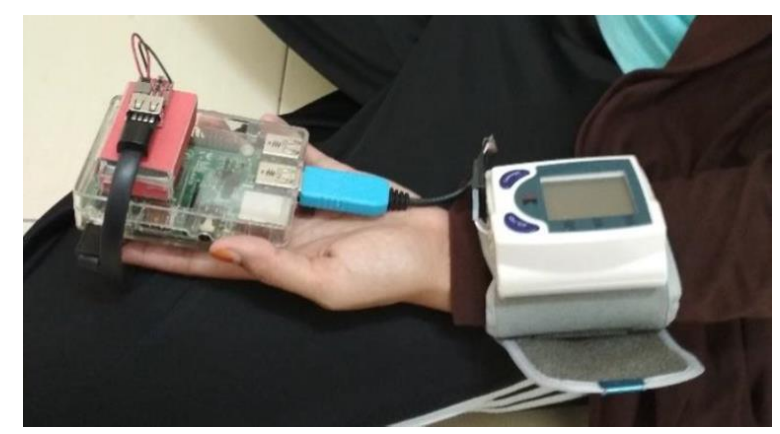

Figure 6. Product prototype

\subsection{Results on Telegram and Gmail applications}

The displays on Telegram application is shown in Figure 7 and the screen capture from Gmail account is depicted in Figure 8. Basically three information were displayed on both applications, the blood pressure readings; the summary of blood pressure readings; and the timestamp about when the information arrived. Based on information from American Heart Association (AHA) [20], the blood pressure is considered as normal if the systolic readings is below $120 \mathrm{mmHg}$ and elevated if the systolic reading between 120 to 129 . The rest is considered as stage 1, 2 and hypertensive. Based on that information, summary is made by programmer according to individual's systolic readings whether the readings are normal, low blood pressure, or high blood pressure.

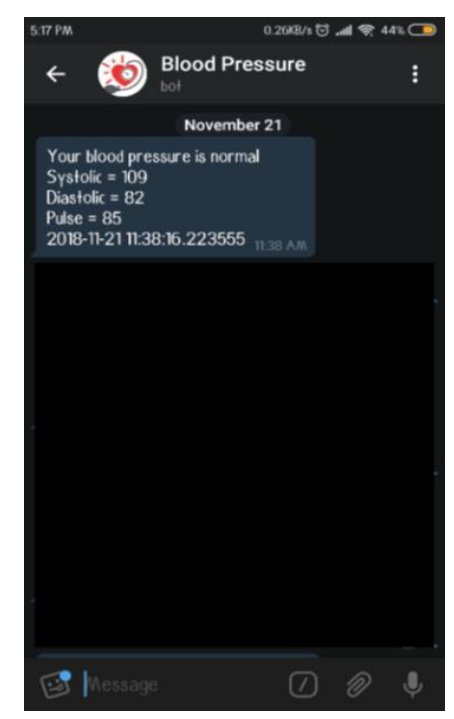

Figure 7. Telegram Application

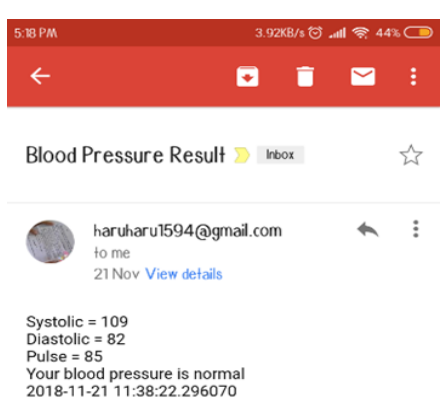

Figure 8. Gmail Application

\subsection{Accuracy of blood pressure based on user's position}

Figure 9 shows the data taken to observe the accuracy of readings based on the position of user. The user is having a normal blood pressure reading at the time the data was taken. Sitting position shows the blood pressure in normal condition, while in the standing position the blood pressure shows in high blood pressure level and at the lying position is at the low blood pressure. The best accuracy of the readings is obtained when the user is in sitting position with hand straight. 


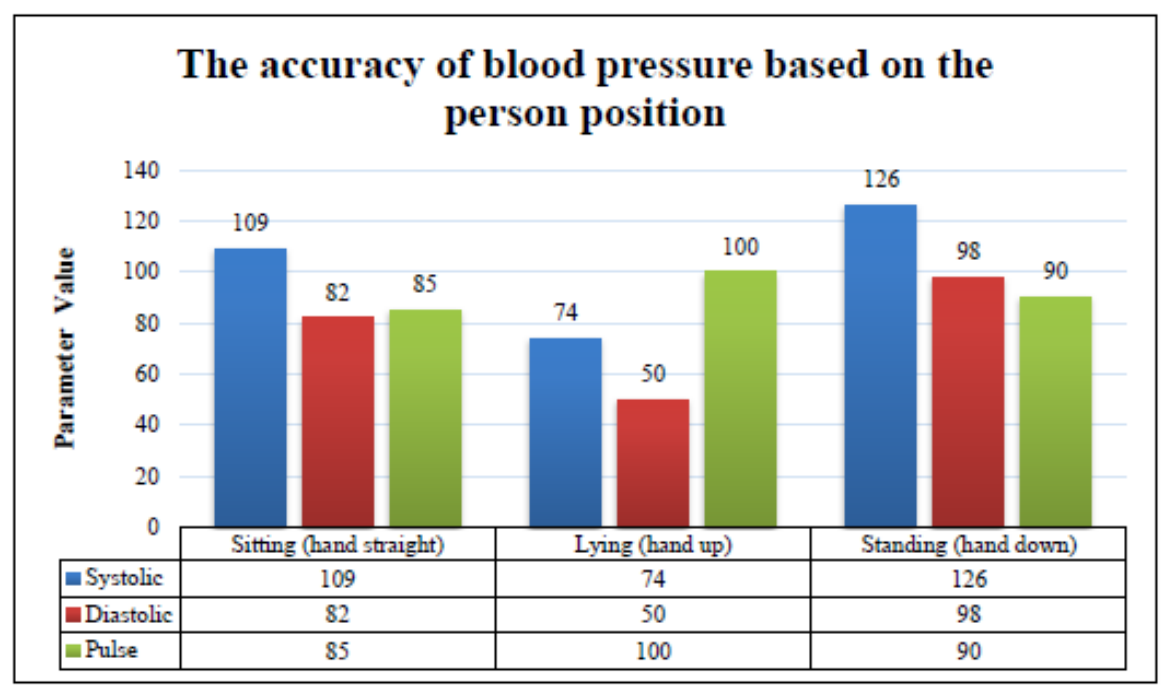

Figure 9. Comparison of received messages duration between $\mathrm{WiFi}$ and Ethernet Cable

\section{CONCLUSION}

This paper presents the design and development of IoT blood pressure monitoring system using Raspberry Pi. Results showed the system is able to read and send the data to both Telegram and Gmail application. The system has been designed and analyzed successfully. In future the connection between Raspberry Pi and blood pressure detector can be made wirelessly so that the design looks more compact. Besides, the design could be extend to read other health items such ECG. Futher more, different types of wireless technologies such as WiFi [21-23], Multi-hop Wireless Network (MWN) [24] and Device-to-Device (D2D) communications [25-27] can be incorporated into the system.

\section{ACKNOWLEDGEMENTS}

Authors would like to acknowledge Faculty of Electrical and Electronic Engineering Technology, Universiti Teknikal Malaysia Melaka (UTeM) and those who give energetic and full support in carrying this research under the grant vote number PJP/2019/FTKEE(7C)/S01671.

\section{REFERENCES}

[1] N. Q. Z Abidin, A. R. Abdullah, N. Norddin, A. Aman, "Online surface condition monitoring system using time frequency distribution on high voltage insulator, Australian Journal of Basic and Applied Sciences, vol. 7, no. 11, pp. 7-14, 2013.

[2] N. Hashim, F. Idris, A. F. Kadmin, S. S. J. Sidek, "Automatic traffic light controller for emergency vehicle using peripheral interface controller", International Journal of Electrical and Computer Engineering (IJECE), vol. 9, no. 3, pp1788-1794, 2019.

[3] B. Mustapha, "Development of a PC interfaced blood pressure meter (EBpms)," M. Eng Thesis, Universiti Teknologi Malaysia. 2008.

[4] N. Hashim, M. A. H. A. Razak, F. Idris, "Home security system using Zigbee," Jurnal Teknologi (Sciences \& Engineering), vol. 74, no. 10, pp. 29-34, 2015.

[5] F. Idris, N. Hashim, AF. Kadmin, LB Yee, "Intelligent fire detection and alert system using labVIEW," International Journal of Electrical and Computer Engineering (IJECE), vol. 9, no. 3, pp 1842-1849, 2019.

[6] T. H. L. Ling, et al., "Blood pressure monitoring device with ZigBee (XBee) wireless protocol and Microsoft visual studio computer interfacing," International Journal of Simulation: Systems, Science and Technology, vol. 16, no. 4 , pp. 9.1-9.8, 2015.

[7] C. Li, X. Hu, and L. Zhang, "The IoT-based heart disease monitoring system for pervasive healthcare service," Procedia Computer Science, vol. 112, pp. 2328-2334, 2017.

[8] D. Gkouskos and J. Burgos, "Towards participatory healthcare of elderly through IoT," Procedia Computer Science. Elsevier B.V., 113, pp. 647-652, 2017.

[9] I. Jahan, M. L. Rahman, A. W. Reza, S. D. Barman, "Systolic Blood Pressure Measurement from Heart Rate using IoT," International Journal of Recent Technology and Engineering (IJRTE), vol. 7, no. 4, pp. 135-138, 2018.

[10] W. A. Salah, A. A. Sneineh, "Development of pulse and blood pressure monitoring system," 2018 IEEE Symposium on Computer Applications \& Industrial Electronics (ISCAIE), 2018. 
[11] A.I. Siam, A. A. Elazm, N. A. El-Bahnasawy, "Smart health monitoring system based on IoT and cloud computing," 1st International Conference on Electronic Engineering, Menoufia University, ICEEM2019, 2019.

[12] W. J. Li, Y. L. Luo, Y. S. Chang, Y. H. Lin, “ A wireless blood pressure monitoring system for personal health management," 32nd Annual International Conference of the IEEE EMBS Buenos Aires, Argentina, 2010.

[13] R. Priyanka, M. Reji, "IoT based health monitoring system using blynk app," International Journal of Engineering and Advanced Technology (IJEAT), vol. 8, no. 6, pp. 78-81, 2019.

[14] K. C. Chowdary, K. Lokesh Krishna, K. L. Prasad and K. Thejesh, "An efficient wireless health monitoring system," 2018 2nd International Conference on I-SMAC (IoT in Social, Mobile, Analytics and Cloud), Palladam, India, pp. 373-377, 2018.

[15] T. J. Swamy and T. N. Murthy, "eSmart: An IoT based intelligent health monitoring and management system for mankind," 2019 International Conference on Computer Communication and Informatics (ICCCI), Coimbatore, Tamil Nadu, India, pp. 1-5, 2019.

[16] N. G. Bolívar Pulgarín, L. D. Cangrejo Aljure and O. J. Salcedo Parra, "eHeart-BP, prototype of the internet of things to monitor blood pressure," 2019 IEEE/ACM International Conference on Connected Health: Applications, Systems and Engineering Technologies (CHASE), Arlington, VA, USA, pp. 58-63, 2019.

[17] V. Vippalapalli and S. Ananthula, "Internet of things (IoT) based smart health care system," 2016 International Conference on Signal Processing, Communication, Power and Embedded System (SCOPES), Paralakhemundi, pp. 1229-1233, 2016.

[18] A. Gutte and R. Vadali, "IoT based health monitoring system using raspberry Pi," 2018 Fourth International Conference on Computing Communication Control and Automation (ICCUBEA), Pune, India, 2018, pp. 1-5.

[19] I. khan et al., "healthcare monitoring system and transforming monitored data into real time clinical feedback based on IoT using raspberry Pi," 2019 2nd International Conference on Computing, Mathematics and Engineering Technologies (iCoMET), Sukkur, Pakistan, 2019, pp. 1-6.

[20] E. J. Benjamin, et al., "Heart Disease and Stroke Statistics-2019 Update," US: AHA journal, vol. 139, no. 10, pp. e56-e528, 2019.

[21] N. Hashim, N. F. A. M. Azmi, F. Idris, N. Rahim, "Smart phone activated door lock using WiFi," ARPN Journal of Engineering and Applied Sciences, vol. 11, no. 5, pp. 3309-3312, 2016.

[22] F. B. Idris and S. H. B. S. Ariffin, "Handoff latency of voice over internet protocol in Mobile IPv6," 2008 IEEE International RF and Microwave Conference, Kuala Lumpur, pp. 197-201, 2008.

[23] H. Ouldzira, A. Mouhsen, H. Lagraini, M. Chhiba, A. Tabyaoui, S. Amrane, "Remote monitoring of an object using a wireless sensor network based on NODEMCU ESP8266," Indonesian Journal of Electrical Engineering and Computer Science (IJEECS), vol. 16, no. 3, pp 1154-1162, 2019.

[24] F. Rahmat, F. Idris, M. Azri, V. Kanathasan, N. Sarimin and M. H. Mohamad, "Performance analysis of VoIP in Multi-hop Wireless Network," 2012 IEEE Asia-Pacific Conference on Applied Electromagnetics (APACE), pp. 51-55, 2012.

[25] F. Idris, "Resource allocation for energy efficient device-to-device communications," Ph.D thesis, The University of Manchester. 2019.

[26] F. Idris, J. Tang and D. K. C. So, "Energy efficient device to device communication by resource efficiency optimization," 2017 IEEE 85th Vehicular Technology Conference (VTC Spring), Sydney, NSW, pp. 1-5, 2017.

[27] F. Idris, et al., "Resource and energy efficient device to device communications in downlink cellular system," 2018 IEEE Wireless Communications and Networking Conference (WCNC), Barcelona, pp. 1-6, 2018. 